\title{
Multilevel modelling, prevalence, and predictors of hypertension in Ghana: Evidence from Wave 2 of the World Health Organization's Study on Global AGEing and adult health
}

Justice Moses Kwaku Aheto ( $\nabla$ justiceaheto@yahoo.com )

University of Ghana https://orcid.org/0000-0003-1384-2461

Getachew A. Dagne

University of South Florida

Research article

Keywords: Multilevel modelling, Binary logistic regression, Hypertension, Risk factors, Hypertension determinants, Developing countries, Sub-Saharan Africa, Ghana

Posted Date: September 28th, 2020

DOI: https://doi.org/10.21203/rs.3.rs-70813/v1

License: (9) This work is licensed under a Creative Commons Attribution 4.0 International License.

Read Full License 
Title:

Multilevel modelling, prevalence, and predictors of hypertension in Ghana: Evidence from Wave 2 of the World Health Organization's Study on Global AGEing and adult health.

\section{Authors:}

Justice Moses K. Aheto ${ }^{1,2 *}$ and Getachew A. Dagne ${ }^{2}$

\section{Authors' Affiliations:}

1Department of Biostatistics, School of Public Health, College of Health Sciences, University of Ghana, Ghana.

${ }^{2}$ College of Public Health, University of South Florida, USA.

\section{*Corresponding author:}

E-mail: justiceaheto@yahoo.com; jmkaheto@ug.edu.gh (JMKA) 


\begin{abstract}
Background: Hypertension is a major public health issue, a critical risk factor for cardiovascular diseases and stroke, especially in developing countries where the rates remain unacceptably high. In Africa, hypertension is the leading driver of cardiovascular disease and stroke deaths. Identification of critical risk factors of hypertension can help formulate targeted public health programmes and policies aimed at reducing the prevalence and its associated morbidity, disability, and mortality. This study attempts to develop multilevel binary logistic regression model, an in-depth statistical model to identify critical risk factors of hypertension to inform interventions aimed at improving cardiovascular health outcomes among adults.
\end{abstract}

Methods: This study used data on 4667 individuals aged $\geq 18$ years from the nationally representative World Health Organization Study on global AGEing and adult health (SAGE) Ghana Wave 2 conducted in 2014/2015. Multilevel regression modelling was applied on final sample of 4381 individuals residing in 3790 households to identify critical risk factors for hypertension based on systolic blood pressure (SBP) (i.e. SBP>140mmHg).

Results: A total of 1273(27.3\%) were hypertensive. Critical risk factors for hypertension identified were aged $\geq 50$ years (OR=5.4, 95\% CI: 4.11-7.09), obese (OR=1.51, 95\% CI: 1.19 1.91), currently married (OR=0.75, 95\% CI: 0.64-0.89), individuals in moderate (OR=1.38, 95\% CI: $1.15-1.65)$ or bad/very bad health state $(\mathrm{OR}=1.35,95 \% \mathrm{CI}: 1.0-1.83)$ and moderate difficulty with self-care (OR=1.64, 95\% CI: 1.1-2.44). Strong unobserved household-level residual variations were found. The results from the variation analyses showed that over $12 \%$ of variance in hypertension could be attributable to residual household-level variations.

Conclusion: Hypertension remains high in Ghana. Addressing the problem of obesity, targeting specific interventions to those aged over 50 years, and improvement in the general health of Ghanaians are paramount to reducing the prevalence and its associated morbidity, disability, and mortality. Lifestyle modification in the form of dietary intake, knowledge provision supported with strong public health message and political will could be beneficial to the management and prevention of hypertension.

Keywords: Multilevel modelling, Binary logistic regression, Hypertension, Risk factors, Hypertension determinants, Developing countries, Sub-Saharan Africa, Ghana. 


\section{Background}

Hypertension remains one of the biggest threats to public health globally, especially in the lowand middle-income countries where the prevalence is the highest as a result of more people residing in these countries, and with greater priority and interest in infectious diseases $[1,2]$. It contributes significantly to the global burden of cardiovascular disease and its related illnesses like stroke, kidney and heart failures, and their resultant premature morbidity, disability, and mortality. Hypertension is responsible for $51 \%$ of deaths from stroke and at least $45 \%$ from heart diseases and overall, it is responsible for about $50 \%$ of deaths from stroke and heart diseases [1,3]. Cardiovascular diseases were the leading cause of death in Africa and accounted for over $16 \%$ of the total deaths in all ages [4]. The number of deaths (1.42 million) in 2017 attributable to cardiovascular diseases represent $61 \%$ increase over that of 1990 . High blood pressure, one of the Non-Communicable Diseases (NCDs), is the leading risk factor for deaths in Africa responsible for nearly two-thirds of the cardiovascular deaths in the region. With a high blood pressure prevalence of $27 \%$ in 2017, Africa is reported to have the highest prevalence globally [5], and is a common cause of medical hospitalization in the region [6] responsible for over $50 \%$ of first time acute stroke $[7,8]$. High blood pressure is expected not to decline anytime soon due to rise in ageing population and urbanization, and its associated sedentary lifestyle, stress, and poor diet [2, 8-10].

Some of the factors known to be associated with hypertension include high body mass index (BMI), older age, race, cigarette smoking, high salt intake, alcohol use, female sex, urban residence, physical inactivity and genetics $[8,11-16]$. Though not a significant problem previously in groups like young and rural populations, hypertension is now a critical public health problem in these groups [8, 17-19].

After the third high-level meeting of the United Nations General Assembly in October 2018, there exist a renewed political will to address NCDs [8, 20, 21]. However, development and application of sound statistical methods are required to analyse the barriers and facilitators of hypertension in order to achieve this ambitious goal. It is against this background that this study attempts to estimate the prevalence, and to employ a multilevel regression modelling approach to quantify household-level variations and to determine critical risk factors for hypertension to inform sound and targeted policies aimed at improving cardiovascular health outcomes among this population. 


\section{Methods}

\section{Data source and study population}

This work was based on the nationally representative World Health Organization Study on global AGEing and adult health (SAGE) Ghana Wave 2 conducted in the period 2014/2015. The survey is a multi-country study with the goal of generating data to complement existing ageing data sources. To allow each household and individual respondent to be assigned a known nonzero selection probability, a multistage cluster sampling strategies were employed where clusters were systematically sampled and households residing in the selected clusters identified/listed, and individuals in those selected households selected for interview. All persons aged 50 years and older were selected from households classified as $\geq 50$ households' and one person aged 18-49 years was selected from a household classified as an '18-49 household' to complete the individual interview. Trained field officers visited sampled households for individual and household interviews. Two separate questionnaires (individual and household) were used during the survey (see additional file 1). In the present study, we merged the individual and household level datasets using a unique individual and household identification number available in the datasets. Among others, data were collected on subjective wellbeing, quality of life, perceived health status, household, and socio-demographic characteristics. WHO SAGE surveys primarily focus on older adults $(\geq 50)$ but for the purpose of comparison, a smaller sample of those aged 18-49 years were also included in the study. Further description of the methods is available at $[22,23]$, and the general WHO SAGE surveys at (https://www.who.int/healthinfo/sage/cohorts/en/).

\section{Outcome variable}

The outcome variable of interest in the study is hypertension status based on systolic blood pressure measurement ( $\mathrm{SBP}>140 \mathrm{mmHg}$ ). The blood pressure readings were taken 3 times between rest periods with one minute between each measurement using Oscillometric device and the measures are standardised as required of such exercise. This study always adopts international standards and procedures in the data collection and analysis, and used the recommended threshold of SBP $>140 \mathrm{mmHg}$ to declare the hypertension status [24] (i.e. $\mathrm{SBP}>140 \mathrm{mmHg}=$ hypertensive coded as 1 , and 0 otherwise) .

\section{Covariates}

This study considered several covariates based on literature on factors influencing hypertension, including other potential health variables yet to be established in the literature as risk factors. These include age, obesity, ethnicity, sex, marital status, type of toilet facility in 
household, health state at the time of the interview, and difficulty with self-care, alcohol consumption, type of cooking fuel, household wall and floor types [2, 11-14, 25-27].

For toilet facilities, the survey asked, "What type of toilet facility do members of your household usually use?" and we grouped the responses as indicated earlier. For the health state today variable, the survey asked, "In general, how would you rate your health today?" and responses recorded. In case of difficulty with self-care, the survey asked, "Overall in the last 30 days, how much difficulty did you have with self-care, such as bathing/washing or dressing yourself?". Regarding alcohol consumption, the survey asked, "Have you ever consumed a drink that contains alcohol (such as beer, wine, spirits)?" with yes or no responses as indicated earlier. For household cooking fuel, the survey asked, "What type of fuel does your household mainly use for cooking?" and we grouped the responses according to primitive, transition and advanced fuels. They survey also collected data on household wall type through the question "What type of wall does your dwelling have?" and we combined the responses as presented earlier. Finally, floor types of households were measured through the question "What type of floor does your dwelling have?". See Table 1 for description and categorization of the variables used in this study.

\section{Statistical analysis}

Descriptive statistics were used to summarize the distribution of selected background characteristics of respondents. Further analyses were conducted to examine individual and household-level factors that might be significantly associated with hypertension and explored unobserved household level effects on the outcome. We extract data on a total of 4667 individuals with valid measurements on systolic blood pressure. Due to missingness in some critical covariates, a final sample of 4381 individuals were used in our final models. Both singlelevel and multilevel (mixed effects) logistic regression models were applied on 4381 individuals residing in 3790 households with complete measurements on hypertension as well as complete measurements on potential explanatory variables considered in the final models. The minimum and the maximum number of individuals living in household was one (1) and seven (7), respectively. The extension of the single level logistic regression model to the multilevel logistic regression model is warranted because of the nested structure of the WHO SAGE dataset where we have individuals clustered within households. Specifically, we applied random intercept multilevel logistic regression models to examine possible differences in hypertension among individuals across households while simultaneously identifying potential risk factors. Thus, unlike the single level logistic model, the multilevel modelling strategy [28] placed certain 
prominence on household level variations in the risk of hypertension among individuals and the extent of clustering of hypertension within a household.

In our model formulation, we let $j$ index level-one unit (i.e. individual respondent) and $k$ for level-two unit (i.e. household the individual belongs), $Y_{j k}$ indicates hypertension variable for individual $j$ in household $k$ and $x_{j k}$ denotes covariate for child $j$ in household $k$ which may be directly related to the individual or the household the individual belongs to. We set up a twolevel random intercept variance components model in a multilevel framework as:

$$
\ln \left\{Y_{j k} /\left(1-Y_{j k}\right)\right\}=\beta_{0}+U_{0 k}+\beta_{1} x_{j k}
$$

with $U_{0 k} \sim \mathrm{N}\left(0, \sigma^{2} \mathrm{u}\right)$. The regression coefficient $\beta_{1}$ is common to all households, $\beta_{0}$ is the average prevalence of hypertension, $U_{0 k}$ is the household-dependent deviation in hypertension prevalence with variance $\sigma^{2}$. The individual-level residual is assumed to follow a standard logistic distribution with mean zero and variance $\pi^{2} / 3$, where $\pi=3.14$ [30]. We extended the model in Equation (1) to include several covariates. For further discussion on multilevel modelling techniques, see Goldstein (1987 and 2003), and Snijders and Bosker (2012). To quantify the proportion of total variation attributable to within-households differences in hypertension, the household-level Variance Partition Coefficient (VPC) [29] was employed, which is defined as VPC $=\left\{\sigma^{2} \mathrm{u} /\left(\sigma^{2} \mathrm{u}+\pi^{2} / 3\right)\right\}^{*} 100$.

Model parameters were obtained using maximum likelihood. The identity covariance structure provided a good fit to the data in the random intercept multilevel logistic regression model. The goodness of fit for the fitted models was examined using a likelihood ratio test (LRT), Akaike Information Criterion (AIC) and Bayesian Information Criterion (BIC). Variance inflation factor (VIF) was used to verify the presence of multicollinearity, and a VIF value $<10$ was declared acceptable [31]. All the analyses were conducted in STATA Version 14 [32]. Backward elimination was employed to select candidate set of risk factors for multivariable logistic regression analysis. To achieve statistical significance, a P-value $<0.05$ was used.

\section{Results}

\section{Participant characteristics}

Out of the 4667 individual respondents, 1273 (27.3\%) were hypertensive ( $92.1 \%$ for $\geq 50$ and $7.9 \%$ for $<50$ years old). Out of 3527 individuals aged $\geq 50$ years, 1172 (33.2\%) were hypertensive, and out of 1140 individuals aged <50 years, 101 (32.2\%) were hypertensive. Approximately $75.6 \%$ of the respondents were at least 50 years old and $58.7 \%$ were females. 
Over $48 \%$ of the respondents were Akan, with the Guan ethnicity in the minority (4.1\%) and over $55 \%$ reported being currently married and about $74 \%$ had fathers with no formal education. Over $12 \%$ were obese and a little over $6 \%$ reported ever using tobacco while over $32 \%$ reported that they did not know high salt diet can cause health problems. Household characteristics included durable material for walls (62.7\%), non-flush toilets (84.5\%), shared toilets (76.6\%) and hard floor (86.3\%) (Table 1).

[ Insert Table 1 around here]

\section{Predictors of hypertension}

The univariable analyses identified age, obesity, sex, marital status, toilet facility, health state, difficulty with self-care, wall type, floor type and ethnicity as significant predictors of hypertension. Significant predictors of hypertension in the multivariable model include age, obesity, marital status, toilet facility, health state and difficulty with self-care.

Comparing the single-level multivariable logistic regression (Table 2) to the multilevel logistic regression model (Table 3), the multilevel model provided a good fit to the data. Thus, the multilevel logistic regression is preferred to the single-level multivariable model.

[ Insert Table 2 around here]

Significant predictors of hypertension in the multilevel model were age, obesity, marital status, health state and difficulty with self-care. Significant unobserved household-level variations in hypertension were found. The results from the variation analyses showed that over $12 \%$ of variance in hypertension could be attributable to residual household-level variations after adjusting for individual and household level factors considered in the multilevel model.

Individuals aged $\geq 50$ years were at increased risk of hypertension compared to those aged 1849 years (OR=5.4, 95\% CI: 4.11-7.09). There was a 51\% increase in the odds of hypertension among individuals who are obese compared to their counterparts who were not obese (OR=1.51, 95\% CI: 1.19-1.91). Individuals who were currently married had $25 \%$ less odds of having hypertension compared to those who were not currently married $(\mathrm{OR}=0.75,95 \% \mathrm{CI}$ : 0.64-0.89). Individuals who rated their health state as moderate or bad/very bad had $38 \%$ and $35 \%$ higher odds of having hypertension, respectively compared to those who rated themselves as good/very good (OR=1.38, 95\% CI: $1.15-1.65$ and $\mathrm{OR}=1.35$, 95\% CI: 1.0-1.83). Those who rated themselves as having moderate difficulty with self-care had $64 \%$ higher odds of having hypertension compared to those who rated themselves as having no difficulty $\mathrm{OR}=1.64,95 \% \mathrm{CI}$ : 1.1-2.44) (Table 3). 
[Insert Table 3 around here]

\section{Discussion}

The study sets out to estimate hypertension prevalence and to develop a novel multilevel logistic regression model to identify critical risk factors of hypertension to help in formulating targeted policies that could improve cardiovascular health among the Ghanaian adults. In this study, a hypertension prevalence of $27.3 \%$ was observed, suggesting that hypertension among Ghanaian adults is still a serious public health issue. This prevalence exceeded the $18 \%$ prevalence observed in her neighbouring country Burkina Faso [27], and other African countries with prevalence of $24.5 \%$ in Kenya [33] and $8 \%$ in Tanzania [34] but lower than the $31 \%$ observed in Nigeria [35]. These differences could be attributable to the setting and study designs. Critical risk factors independently associated with hypertension while adjusting for the unobserved household-level effects were age, obesity, marital status, health state and difficulty with self-care.

Of critical importance to this study is the quantification of residual household-level effects on hypertension prevalence among adults, which represent variations in household-level hypertension prevalence that cannot be explained by the available covariates in our multilevel model. Generally, the health and the general wellbeing of individuals is heavily reliant on the households they belong to. Thus, the households determine the resources, opportunities and risks available to the individual over their life course [36-38]. We observed strong residual household-level variations in hypertension and that over $12 \%$ of variation in hypertension prevalence in adults could be attributable to unobserved household-level variations after adjusting for the risk factors in our model. This could be as a result of household-level, social and environmental factors not considered in our model.

The study broadly supports earlier studies that examined determinants of hypertension in developing countries. For instance, older age group, obesity, rating health state as moderate or bad/very bad, and rating level of difficulty for self-care as moderate were associated with increased odds of hypertension in adults, and those who were currently married had reduced odds of hypertension $[3,11-15,27,35,39,40]$. The association between hypertension and the older age group observed in this study could be attributable to variations in the arterial structure and function, notably arterial stiffening with adverse consequences on cardiac structure and function $[35,41,42]$. Individuals who were currently married had reduced odds of hypertension compared to those who were not currently married. Protective effects for marriage on health has been established in previous studies $[43,44]$. However, this finding is 
not consistent with a previous study that observed that married women had increased odds of hypertension but no such association was found in men in the same study [3]. It also contradicts a previous study [45] that did not find an association between marital status and hypertension but this could be as a result of the setting or how the variable marital status was categorised. Marital status is a critical social characteristic which is well known to predict a range of health outcomes such as cardiovascular illnesses $[46,47]$ and mortality in general $[44,48]$.

Obesity, which is one of the modifiable risk factors considered in this study showed an association with hypertension. Individuals who were obese had higher odds of hypertension compared to their counterparts who were not obese, a finding which is consistent with previous studies [27, 33-35, 40, 49]. The association between hypertension and obesity had been established and well known, and reducing BMI is part of the advice provided in the treatment of hypertension $[27,50]$. This could be due to metabolic and endocrine disorders as a result of increasing BMI [51].

Individuals who rated their health state as moderate or bad/very bad on the day of the interview had increased odds of hypertension compared to those who rated their health state as good/very good. Also, those who rated their difficulty with self-care as moderate had increased odds of hypertension compared to their counterparts who rated themselves as having no difficulty. These findings are plausible because in a previous study, a hypertensive group had significantly lower age-adjusted health status scores compared to non-hypertensive group [52]. To the best of our knowledge, this is the first study to have established an association between hypertension and health variables like self-reported health state and difficulty with self-care. The significant association between hypertension and these health variables suggest the need to improve the overall health of Ghanaian adults to reduce and prevent the high prevalence of hypertension among this group.

One of the major public health issues in Ghana presently is the rise in the prevalence of NCDs $[53,54]$. The findings in the present study provided vital and current information on prevalence and critical risk factors for hypertension that can be used by policymakers and health practitioners for better understanding of hypertension and its prevention and management, which could lead to more effective prevention approaches, patient management and improved cardiovascular outcomes. The study highlights the need to address the problem of obesity, targeting specific interventions to those aged over 50 years, and improvement in the general health of the Ghanaian population as a primary intervention is warranted as part of an overall strategy to reduce the hypertension prevalence and its resultant premature morbidity, disability and mortality. 


\section{Strength and limitation of the study}

The strengths of this study include the fact that it utilised data from a nationally representative population-based survey which is globally respected for its sound survey methods and sound data quality on individuals, their households and communities in which they reside. The large samples drawn nationwide permits generalization of findings to the population of adults in Ghana and that of adults from other similar populations globally. The study also used a novel multilevel modelling approach, permitting the study of unobserved household-level effects on hypertension. Thus, providing much more information about why individuals from certain households are more likely to be hypertensive while others are not and at the same time investigating underlying associations between hypertension and the risk factors which could not have been possible using single-level logistic regression approach. Despite these strengths, the study has limitations and so the findings should be interpreted with caution. For example, the analytical techniques employed in the analysis of the data could not establish cause and effect relationship between hypertension and the risk factors considered. Also, some of the risk factors such as health state and difficulty with self-care were based on self-reports and so could introduce reporting bias. The variation in hypertension prevalence among those aged $<50$ and $\geq 50$ years should be interpreted with caution because the WHO SAGE surveys primarily focus on older adults and so always sample more older adults ( $\geq 50$ years) compared to younger adults (18-49 years).

\section{Conclusion}

Findings from the study show that prevalence of hypertension remains high among Ghanaian adults. This study developed a novel multilevel binary logistic regression model which captures unobserved household-level effects and identified critical risk factors of hypertension which can aid formulation of health policies and intervention strategies that will improve cardiovascular health outcomes of the Ghanaian adults. Lifestyle modification in the form of dietary intake, knowledge provision supported with strong public health messages and political will could be beneficial to the management and prevention of hypertension. Active screening for hypertension should be encouraged to identify undiagnosed cases to minimise the danger of stroke and cardiovascular diseases, but there is the need to improve the health systems and services in the country to reap the full benefits of such interventions. There is also the need to target younger populations to minimize their risk of developing hypertension during 
adulthood/old age. Further study to identify as-yet unidentified risk factors that might account for the substantial unexplained household-level variations in adult hypertension is warranted.

\author{
Abbreviations \\ AIC: Akaike Information Criterion \\ BIC: Bayesian Information Criterion \\ BMI: Body Mass Index \\ LRT: Likelihood Ratio Test \\ NDCs: Non-Communicable Diseases \\ SBP: Systolic Blood Pressure \\ VIF: Variance Inflation Factor \\ VPC: Variance Partition Coefficient
}

\title{
Declarations
}

\section{Ethics approval and consent to participate}

SAGE was approved by the World Health Organization's Ethical Review Board (reference number RPC149) and the Ethical and Protocol Review Committee, College of Health Sciences, University of Ghana, Accra, Ghana. Written informed consent was obtained from all study participants. All methods were performed in accordance with the relevant guidelines and regulations.

\section{Consent to publish}

Not applicable

\section{Availability of data and materials}

The datasets analysed during the current study are freely available upon making official request to WHO-SAGE Team through the WHO website at http://www.who.int/healthinfo/sage/cohorts/en/. Individual researchers granted permission to use the data are not allowed to make the data (in any form) publicly available to third parties.

\section{Competing interests}

The authors declare that they have no competing interests.

\section{Funding}

Not applicable

\section{Author contributions}

JMKA developed the concept and analysed the data and wrote the first draft manuscript. JMKA and GAD contributed to the writing and reviewing of the various sections of the manuscript. All 
the authors reviewed the final version of the manuscript before submission. All authors read and approved the final manuscript.

\section{Acknowledgements}

This Fellowship was supported by the University of Ghana Building a New Generation of Academics in Africa (BANGA-Africa) Project with funding from the Carnegie Corporation of New York. The statements made and views are solely the responsibility of the authors. We are also grateful to the WHO SAGE Team, especially Professors Biritwum and Yawson of the Ghana Team and all respondents and interviewers who made the SAGE survey in Ghana possible. The Ministry of Health, Ghana, is supportive of SAGE. The University of Ghana's Department of Community Health contributed training facilities, data entry support, and storage of materials. The Ghana Statistical Office provided the sampling information for the sampling frame and updates. 


\section{References}

1. World Health Organization (WHO): A Global Brief on Hypertension: Silent Killer, Global Public Health Crisis (Accessed on 30/03/2019 and available at https://www.who.int/cardiovascular diseases/publications/global brief hype rtension/en/). In. Geneva: WHO; 2013.

2. van de Vijver S, Akinyi H, Oti S, Olajide A, Agyemang C, Aboderin I, Kyobutungi C: Status report on hypertension in Africa--consultative review for the 6th Session of the African Union Conference of Ministers of Health on NCD's. Pan Afr Med J 2013, 16:38.

3. Tuoyire DA, Ayetey H: GENDER DIFFERENCES IN THE ASSOCIATION BETWEEN MARITAL STATUS AND HYPERTENSION IN GHANA. J Biosoc Sci 2018:1-22.

4. Global Burden of Disease: GBD Compare Data Visualization [https://vizhub.healthdata.org/gbd-compare/]

5. Zhou B, Bentham J, Di Cesare M, Bixby H, Danaei G, Cowan MJ, Paciorek CJ, Singh G, Hajifathalian K, Bennett JE: Worldwide trends in blood pressure from 1975 to 2015: a pooled analysis of 1479 population-based measurement studies with 19: 1 million participants. Lancet 2017, 389(10064):37-55.

6. Etyang AO, Gerard Scott JAJGha: Medical causes of admissions to hospital among adults in Africa: a systematic review. Glob Health Action 2013, 6(19090).

7. O'Donnell MJ, Chin SL, Rangarajan S, Xavier D, Liu L, Zhang H, Rao-Melacini P, Zhang X, Pais $\mathrm{P}$, Agapay S: Global and regional effects of potentially modifiable risk factors associated with acute stroke in 32 countries (INTERSTROKE): a case-control study. Lancet 2016, 388(10046):761-775.

8. Bosu WK, Reilly ST, Aheto JMK, Zucchelli E: Hypertension in older adults in Africa: A systematic review and meta-analysis. PLoS One 2019, 14(4):e0214934.

9. Adeloye D, Basquill C: Estimating the prevalence and awareness rates of hypertension in Africa: a systematic analysis. PLoS One 2014, 9(8):e104300.

10. Zhou B, Bentham J, Di Cesare M, Bixby H, Danaei G, Cowan MJ, Paciorek CJ, Singh G, Hajifathalian K, Bennett JE et al: Worldwide trends in blood pressure from 1975 to 2015: a pooled analysis of 1479 population-based measurement studies with 19.1 million participants. Lancet 2017, 389(10064):37-55.

11. Dramé ML, Houehanou C, Sogbohossou P, Paré R, Ekambi A, Mizéhoun-Adissoda C, Houinato D, Gyselinck K, Marx M, Martins MRO et al: Determinants of High Blood Pressure and Quality of Management in Three Regions of Benin. Open Journal of Epidemiology 2018, 8(01):14.

12. Bosu WK: Epidemic of hypertension in Ghana: a systematic review. BMC Public Health 2010, 10:418.

13. Joseph-Shehu EM, Ncama BP: Evaluation of health status and its predictor among university staff in Nigeria. BMC Cardiovasc Disord 2018, 18(1):183.

14. Mohamed SF, Mutua MK, Wamai R, Wekesah F, Haregu T, Juma P, Nyanjau L, Kyobutungi C, Ogola E: Prevalence, awareness, treatment and control of hypertension and their determinants: results from a national survey in Kenya. BMC Public Health 2018, 18(3):1219.

15. Laxmaiah A, Meshram II, Arlappa N, Balakrishna N, Rao KM, Reddy CG, Ravindranath M, Kumar S, Kumar H, Brahmam GN: Socio-economic \& demographic determinants of hypertension \& knowledge, practices \& risk behaviour of tribals in India. Indian J Med Res 2015, 141(5):697-708. 
16. Nyarko SH: Prevalence and Sociodemographic Determinants of Hypertension History among Women in Reproductive Age in Ghana. Int J Hypertens 2016, 2016:3292938.

17. Addo J, Amoah AGB, Koram KA: The changing patterns of hypertension in Ghana: a study of four rural communities in the Ga district. Ethn Dis 2006, 16:894-899.

18. Okeahialam BN, Ogbonna C, Otokwula AE, Joseph DE, Chuhwak EK, Isiguzoro IO: Cardiovascular epidemiological transition in a rural habitat of Nigeria: the case of Mangu Local Government Area. West Afr J Med 2012, 31(1):14-18.

19. Awuah RB, Anarfi JK, Agyemang C, Ogedegbe G, Aikins Ad-G: Prevalence, awareness, treatment and control of hypertension in urban poor communities in Accra, Ghana. J Hypertens 2014, 32(6):1203-1210.

20. United Nations General Assembly: Political declaration of the third high-level meeting of the General Assembly on the prevention and control of noncommunicable diseases. In: Resolution adopted by the General Assembly on 10 October 2018: 73rd Session, Agenda Item 119. New York: UN; 2018.

21. Islam SM, Purnat TD, Phuong NT, Mwingira U, Schacht K, Fröschl G: Non-communicable diseases (NCDs) in developing countries: a symposium report. Global Health 2014, 10:81.

22. Charlton K, Ware LJ, Menyanu E, Biritwum RB, Naidoo N, Pieterse C, Madurai SL, Baumgartner J, Asare GA, Thiele E et al: Leveraging ongoing research to evaluate the health impacts of South Africa's salt reduction strategy: a prospective nested cohort within the WHO-SAGE multicountry, longitudinal study. BMJ Open 2016, 6(11): 013316.

23. Kowal P, Chatterji S, Naidoo N, Biritwum R, Fan W, Lopez Ridaura R, Maximova T, Arokiasamy P, Phaswana-Mafuya N, Williams S et al: Data Resource Profile: The World Health Organization Study on global AGEing and adult health (SAGE). International Journal of Epidemiology 2012, 41(6):1639-1649.

24. Chobanian AV, Bakris GL, Black HR, Cushman WC, Green LA, Izzo JL, Jones DW, Materson BJ, Oparil S, Wright JT et al: The Seventh Report of the Joint National Committee on Prevention, Detection, Evaluation, and Treatment of High Blood Pressure: the JNC 7 report. JAMA 2003, 289(19):2560-2572.

25. Echouffo-Tcheugui JB, Batty GD, Kivimäki M, Kengne AP: Risk models to predict hypertension: a systematic review. PLoS One 2013, 8(7):e67370.

26. Fava C, Sjögren M, Montagnana M, Danese E, Almgren P, Engström G, Nilsson P, Hedblad B, Guidi GC, Minuz $P$ et al: Prediction of blood pressure changes over time and incidence of hypertension by a genetic risk score in Swedes. Hypertension 2013, 61(2):319-326.

27. Soubeiga JK, Millogo T, Bicaba BW, Doulougou B, Kouanda S: Prevalence and factors associated with hypertension in Burkina Faso: a countrywide cross-sectional study. BMC Public Health 2017, 17(1):64.

28. Goldstein H: Multilevel Statistical Models, 3rd edn. London: Arnold; 2003.

29. Steele F, Goldstein H, Rao C, Sinharay S: Multilevel Models in Psychometrics. Psychometrics 2007, 26:401-420.

30. Hedeker D, Gibbons RD: MIXOR: a computer program for mixed-effects ordinal regression analysis. Comput Methods Programs Biomed 1996, 49(2):157-176.

31. Hair JFJ, Anderson RE, Tatham RL, Black WC: Multivariate Data Analysis 3edn. New York: Macmillan; 1995.

32. StataCorp: Stata Statistical Software: Release 14. In. College Station, TX: StataCorp LP. ; 2015.

33. Mohamed SF, Mutua MK, Wamai R, Wekesah F, Haregu T, Juma P, Nyanjau L, Kyobutungi C, Ogola E: Prevalence, awareness, treatment and control of hypertension and their determinants: results from a national survey in Kenya. BMC Public Health 2018, 18(Suppl 3):1219. 
34. Mosha NR, Mahande M, Juma A, Mboya I, Peck R, Urassa M, Michael D, Todd J: Prevalence,awareness and factors associated with hypertension in North West Tanzania. Glob Health Action 2017, 10(1):1321279.

35. Ogah OS, Madukwe O0, Chukwuonye II, Onyeonoro UU, Ukegbu AU, Akhimien MO, Onwubere BJ, Okpechi IG: Prevalence and determinants of hypertension in Abia State Nigeria: results from the Abia State Non-Communicable Diseases and Cardiovascular Risk Factors Survey. Ethn Dis 2013, 23(2):161-167.

36. Aheto JMK, Keegan TJ, Taylor BM, Diggle PJ: Childhood Malnutrition and Its Determinants among Under-Five Children in Ghana. In., vol. 29: Paediatric and Perinatal Epidemiology; 2015: 552-561.

37. Aheto JMK: Predictive model and determinants of under-five child mortality: evidence from the 2014 Ghana demographic and health survey. BMC Public Health 2019, 19(1):64.

38. Adekanmbi VT, Kayode GA, Uthman OA: Individual and contextual factors associated with childhood stunting in Nigeria: a multilevel analysis. Maternal and Child Nutrition 2013, 9(2):244-259.

39. Ware LJ, Chidumwa G, Charlton K, Schutte AE, Kowal P: Predictors of hypertension awareness, treatment and control in South Africa: results from the WHO-SAGE population survey (Wave 2). J Hum Hypertens 2019, 33(2):157-166.

40. Bosu WK: Determinants of Mean Blood Pressure and Hypertension among Workers in West Africa. Int J Hypertens 2016, 2016:3192149.

41. Aronow WS, Fleg JL, Pepine CJ, Artinian NT, Bakris G, Brown AS, Ferdinand KC, Ann Forciea M, Frishman WH, Jaigobin C et al: ACCF/AHA 2011 expert consensus document on hypertension in the elderly: a report of the American College of Cardiology Foundation Task Force on Clinical Expert Consensus documents developed in collaboration with the American Academy of Neurology, American Geriatrics Society, American Society for Preventive Cardiology, American Society of Hypertension, American Society of Nephrology, Association of Black Cardiologists, and European Society of Hypertension. J Am Coll Cardiol 2011, 57(20):2037-2114.

42. Williams B: Vascular ageing and interventions: lessons and learnings. Ther $A d v$ Cardiovasc Dis 2016, 10(3):126-132.

43. Manzoli L, Villari P, M Pirone G, Boccia A: Marital status and mortality in the elderly: a systematic review and meta-analysis. Soc Sci Med 2007, 64(1):77-94.

44. Kaplan RM, Kronick RG: Marital status and longevity in the United States population. J Epidemiol Community Health 2006, 60(9):760-765.

45. Schwandt HM, Coresh J, Hindin MJ: Marital Status, Hypertension, Coronary Heart Disease, Diabetes, and Death Among African American Women and Men: Incidence and Prevalence in the Atherosclerosis Risk in Communities (ARIC) Study Participants. J Fam Issues 2010, 31(9):1211-1229.

46. Brummett BH, Barefoot JC, Siegler IC, Clapp-Channing NE, Lytle BL, Bosworth HB, Williams RB, Mark DB: Characteristics of socially isolated patients with coronary artery disease who are at elevated risk for mortality. Psychosom Med 2001, 63(2):267-272.

47. Lett HS, Blumenthal JA, Babyak MA, Strauman TJ, Robins C, Sherwood A: Social support and coronary heart disease: epidemiologic evidence and implications for treatment. Psychosom Med 2005, 67(6):869-878.

48. House JS: Social isolation kills, but how and why? Psychosom Med 2001, 63(2):273274.

49. Ibrahim MM, Damasceno A: Hypertension in developing countries. Lancet 2012, 380(9841):611-619.

50. Chalmers J: The 1999 WHO-ISH Guidelines for the Management of Hypertension. Med J Aust 1999, 171(9):458-459. 
51. Akintunde AA, Akinwusi PO, Adebayo RA, Ogunyemi S, Opadijo OG: Burden of obesity in essential hypertension: pattern and prevalence. Niger J Clin Pract 2010, 13(4):399-402.

52. Lawrence WF, Fryback DG, Martin PA, Klein R, Klein BEK: Health status and hypertension: A population-based study. Journal of Clinical Epidemiology 1996, 49(11):1239-1245.

53. de-Graft Aikins A, Addo J, Ofei F, Bosu W, Agyemang C: Ghana's burden of chronic noncommunicable diseases: future directions in research, practice and policy. Ghana Med J 2012, 46(2 Suppl):1-3.

54. Ministry of Health (MOH): National Policy for the Prevention and Control of Chronic Non-Communicable Diseases in Ghana. In. Accra: MOH; 2012.

\section{Additional files}

Additional file 1: Individual and household questionnaires used in the main SAGE survey 


\section{Supplementary Files}

This is a list of supplementary files associated with this preprint. Click to download.

- Additionalfile1.pdf 